\title{
Atopic Dermatitis: Insights on Pathogenesis, Evaluation and Management
}

Karagiannidou $A^{1}$, Botskariova $S^{1}$, Farmaki $E^{2}$, Imvrios $\mathbf{G}^{3}$ and Mavroudi $A^{1 *}$

${ }^{1}$ Third Pediatric Department of the Aristotle University of Thessaloniki, Greece

${ }^{2}$ First Pediatric Department of the Aristotle University of Thessaloniki, Greece

${ }^{3}$ Organ Transplantation Unit of the Aristotle University of Thessaloniki, Greece

\begin{abstract}
Background: Atopic Dermatitis (AD) is a highly pruritic chronic inflammatory skin disease that commonly presents during early childhood. Several studies indicate that the disease is very common in western world with lifetime prevalence in children of $10 \%$ to $20 \%$.

Data sources: We make recommendations regarding the evaluation and management of AD in children based on systematic literature searches using the best-available evidence from PubMed, Medline, Google Scholar, NICE, the American Academy of Dermatology and the World Allergy Organization.

Results: $A D$ has an immunologic basis. Both innate and adaptive immune responses are impaired in $A D$ patients. Intense pruritus is a hallmark of the disease which leads to extensive scratching and further breakdown of the skin barrier. Treatment of AD may be topical or systemic. Topical corticosteroids and calcineurin inhibitors are used as topical anti-inflammatory agents. Patients should be carefully instructed in the use of topical glucocorticoids to avoid side effects.
\end{abstract}

Conclusions: Treatment of atopic eczema should be based on a "stepped-care plan" where treatments are stepped up or down depending on the assessment of the state of the child's skin by the physician. Physicians who treat children with mild to moderate $A D$ should tell children and their caregivers that $A D$ is a lifelong illness.

Keywords: Atopic dermatitis; Eczema; Evaluation; Management; Children

\section{Introduction}

Atopic Dermatitis (AD) is a highly pruritic chronic inflammatory skin disease that commonly presents during early childhood [1] and is often thought as synonymous with eczema. In several cases atopic dermatitis is the first manifestation of atopy and is frequently associated with personal and family history of respiratory allergy and have profound effects on patient's lives, career, choices and social interactions [2]. According to the recommendation of the World Allergy Organization in 2004 , the general term for a local inflammation of the skin should be "dermatitis", while proposing the term "eczema" to replace the term previously used as "syndrome eczema/dermatitis" [3]. They also recommend limiting the use of the term "atopic eczema" when a mediation IgE is demonstrated in the pathophysiology of the disease, and "non-atopic eczema" when it is discarded [4].

\section{Epidemiology}

Several studies indicate that the disease is very common in Western world with lifetime prevalence in children of $10 \%$ to $20 \%[5,6]$. There has been a culmination of a twofold to threefold increase in the prevalence of AD since the 1970s.

\section{Genetics}

The risk that the disorder will be genetically transmitted is increased when the mother is affected. There has been considerable interest in the potential role of chromosome $5 q$ $31-33$ as it contains a clustered family of cytokine genes that is IL-3, IL-4, IL-5, IL-13, and GM-CSF, which are expressed by Th2 cells [7]. Case control comparisons have suggested a genotypic association between $\mathrm{T}$ allele of the $-590 \mathrm{C} / \mathrm{T}$ polymorphism of the IL- 4 gene promoter region and $\mathrm{AD}$. The fact that this allele is associated with increased IL- 4 gene promoter activity suggests that it may increase allergic responses in AD. Similarly, IL-13 coding region variants, a gain-of-function polymorphism in the subunit of the IL-4 receptor (located on chromosome 16q12), and a functional mutation in the promoter region of RANTES (located on chromosome 17q11) have been reported in $\mathrm{AD}$. There have been controversial linkage findings between $\mathrm{AD}$ and markers on chromosome 11q13, including the gene encoding for the $\beta$-chain of the high affinity receptor for IgE (FceRI $\beta$ ). Most of these studies included patients with elevated IgE levels. These candidate gene approaches have, therefore, identified genes that suggest that $\mathrm{AD}$ has a common genetic basis with other atopic diseases [8]

An association between a specific polymorphism in the mast cell chymase gene and $\mathrm{AD}$ that has no association with asthma or allergic rhinitis has been identified [7,9]. This finding suggests that a genetic variant of mast cell chymase, which is a serine protease secreted by skin mast cells, may have organ specific-effects and contribute to the genetic susceptibility for $\mathrm{AD}$. $\mathrm{AD}$ has also been associated with a lowproducer transforming growth factor beta cytokine genotype [10]. Because transforming growth factor beta is an important regulatory gene that down-regulates $\mathrm{T}$ cell activation, a low production genotype may contribute to increased skin inflammation.

A study by Turner et al. reports a linkage for AD on chromosome $3 q 21$ in families of German and Scandinavian children [11]. This region encodes the costimulatory molecules CD80 and CD86 and therefore

*Corresponding author: Antigoni Mavroudi, 66 Spirou Loui St, PC: 54352 Pilea, Konstantinopolitika, Thessaloniki, Greece, Tel: 00302310909632; Fax: 00302310992981; E-mail: antigonemavrudi@gmail.com

Received August 27, 2014; Accepted October 06, 2014; Published October 13 2014

Citation: Karagiannidou A, Botskariova S, Farmaki E, Imvrios G, Mavroudi A (2014) Atopic Dermatitis: Insights on Pathogenesis, Evaluation and Management. J Allergy Ther 5: 195. doi:10.4172/2155-6121.1000195

Copyright: (c) 2014 Karagiannidou A, et al. This is an open-access article distributed under the terms of the Creative Commons Attribution License, which permits unrestricted use, distribution, and reproduction in any medium, provided the original author and source are credited. 
may modulate $\mathrm{T}$ cell responses. Another screening study by Cookson et al. $[12,13]$ reported linkage of $\mathrm{AD}$ to loci on chromosomes 1q21, $17 \mathrm{q} 25$ and $20 \mathrm{p}$. Interestingly, these same regions are known to contain psoriasis susceptibility genes, which suggests common candidate genes involved in the control of skin inflammation. This suggests that $\mathrm{AD}$ is influenced by genes that modulate skin responses independent of allergic mechanisms.

\section{Pathogenesis}

Interactions between susceptibility genes, the host's environment and immunologic factors contribute to the pathogenesis of $\mathrm{AD}$. Although most genetic studies have focused on immunological mechanisms, a primary epithelial barrier defect has been anticipated. Filaggrin is a key protein that facilitates terminal differentiation of the epidermis and formation of the skin barrier. It has been shown that two independent loss-of-function genetic variants (R510X and 2282de14) in the gene encoding filaggrin are very strong predisposing factors for atopic dermatitis [14]. Filaggrin is the main source of several major components of natural moisturizing factor of the stratum corneum including pyrrolidone carboxylic acid and urocanic acid. A reduced level of pyrrolidone carboxylic acid and urocanic acid in patients with fillagrin deficiency may be regarded an expected finding [15]. The notion that $\mathrm{AD}$ has an immunologic basis is supported by the observation that primary $\mathrm{T}$ cell immunodeficiency disorders are frequently associated with elevated serum IgE levels and eczematoid lesions.

\section{Systemic Immune Response}

In patients with $\mathrm{AD}$ both innate and adaptive immune responses are impaired. Intense pruritus is a hallmark of $\mathrm{AD}$ which inevitably leads to extensive scratching and ultimately further breakdown of the skin barrier. It is clear that an intact and functional skin barrier (stratum corneum) is required for an effective cutaneous innate immune response. Pattern-recognition receptors- composed of mannan-binding lectins and surfactant proteins recognize unique sugars present on both gram-positive and gram-negative bacteria, fungi, and viruses. They can act directly as opsonins by coating the pathogen and making them accessible for phagocytosis or they can directly activate the complement pathway. Mannan-binding lectin deficiency has been shown to predispose individuals to bacterial and viral infections, including HSV and $S$. aureus. It was reported that a mutation in the Toll-Like Receptor 2 gene R753Q was found with increased frequency in patients with $\mathrm{AD}$ and that it was correlated with more severe phenotype, higher serum total IgE levels, and greater susceptibility to $S$. aureus colonization [16]

The IL-1 receptor pathway has been implicated for defective host immune response to $S$. aureus probably due to impaired neutrophil chemotaxis in response to $S$. aureus. Because inflammatory skin disease are known to be exacerbated by stress, it can be hypothesized that the stress-induced release of corticotrophin-releasing hormone and the ensuing reduction of IL-18 and IL- $1 \beta$ levels might also play a role in the susceptibility to cutaneous infections in patients with $\mathrm{AD}$ [17].

Children with AD have been shown to have reduced levels of soluble CD14 compared with non-atopic children. The lower levels of soluble CD14 observed in children with AD might be due to a reduced capacity to respond to microbial signal [18].

A study demonstrated that the sweat of subjects with $\mathrm{AD}$ was deficient in antimicrobial peptides compared with the sweat of healthy subjects. The antimicrobial properties of these peptides arise from their ability to integrate into and disrupt the cellular membrane of the offending organism [19].

Studies have demonstrated various poly-morphonuclear defects in subjects with AD. These include impaired phagocytic function and a reduced capacity to produce reactive oxygen species. Additionally patients with $\mathrm{AD}$ had defective poly-morphonuclear chemotactic activity which correlated with the disease severity and the presence of cutaneous infections [20].

In the peripheral blood of patients with $\mathrm{AD}$ increased homing $\mathrm{T}$ cells producing interleukin (IL)-4, IL-5, and IL-13 but little interferon (INF)- $\gamma$ have been found. These immunologic alterations are important because IL- 4 and IL-13 are the only cytokines that induce germ line transcription at the $\mathrm{C} \varepsilon$ exon, thereby promoting isotype switching to IgE. IL-4 and IL-13 also induce the expression of vascular adhesion molecule-1 involved in eosinophil infiltration and down-regulate Th1-type cytokine activity. IL-5 plays a key role in the development, activation, and cell survival of eosinophils. In contrast IFN- $\gamma$ inhibits IgE synthesis as well as the proliferation of Th2 cells and expression of the IL- 4 receptor on T cells [8]. The decreased IFN- $\gamma$ produced by $\mathrm{T}$-cells from $\mathrm{AD}$ patients may be the result of reduced production of IL-18 [21].

Th2 immune response in $\mathrm{AD}$ is supported by a number of determinants. These include the cytokine milieu in which $\mathrm{T}$ cell development is taking placing, pharmacologic factors, the costimulatory signals used during $\mathrm{T}$ cell activation, and the AntigenPresenting Cell (APC).

Mononuclear cells from patients with AD have increased cyclic adenosine monophosphate (cAMP) phosphodiesterase (PDE) enzyme activity [22]. This cellular abnormality contributes to the increased IgE synthesis by B cells and the IL-4 production by T cells in AD as IgE and IL-4 production is decreased in vitro by PDE inhibitors.

Co-stimulatory signals, for example, interactions between CD80 or CD86 on APCs and CD28 on T cell receptors with the $\mathrm{MCH}$ plus peptide complex on APC in order to activate resting T cells. The expression of the co-stimulatory molecule, CD86, on B cells of AD patients is significantly higher than in normal patients. Importantly, total serum IgE from $\mathrm{AD}$ patients and normal subjects correlated significantly with CD86 expression on B cells. Anti-human CD86 significantly decreased IgE production by peripheral blood mononuclear cells stimulated with IL-4 and anti-CD40mAb. These data support the concept that CD86 expression in $\mathrm{AD}$ promotes IgE synthesis. IL-4 and IL-13 have also been found to induce CD86 expression on B cells, thereby providing an amplification loop for IgE synthesis in $\mathrm{AD}[23,24]$.

\section{Skin Immunopathology}

\section{Cytokine expression}

Acute lesions are characterized by lymphocytic infiltrate which consists predominantly of activated memory $\mathrm{T}$ cells and have significantly greater number of cells producing IL-4, IL-5 and IL-13 but not significant numbers of IFN- $\gamma$ or IL-12 mRNA expressing cells.

Chronic AD skin lesions have significantly fewer IL-4 and IL-13 mRNA expressing cells, but, greater numbers of IL-5, GranulocyteMacrophage Colony-Stimulating Factor (GM-CSF) IL-12 and INF- $\gamma$ mRNA expressing cells than acute AD. IL-5 and GM-CSF probably contribute to the increased numbers of eosinophils and macrophages. The increased expression of IL-12 in chronic AD skin lesions is of interest in that cytokine plays key role in IFN- $\gamma$ production. Its 
expression in eosinophils and/or macrophages may initiate the switch to Th1 or Th0 cell development in chronic AD [25].

Activated $\mathrm{T}$ cells infiltrating the skin of $\mathrm{AD}$ patients have also been found to induce keratinocyte apoptosis which contributes to the spongiotic process found in $\mathrm{AD}$ lesions [26].

\section{Antigen-presenting cells}

$\mathrm{AD}$ skin contains an increased number of IgE-bearing LCs, which appear to play an important role in cutaneous allergen presentation to Th2 cells. IgE-bearing LCs that have captured allergen are likely to activate memory Th2 cells in atopic skin but may also migrate to the lymph nodes to stimulate naïve $\mathrm{T}$ cells there to expand the pool of systemic Th2 cells [27]. Normal individuals and patients with respiratory allergy have low-level surface expression of FceRI on their LCs, whereas FCeRI is expressed at high levels in the inflammatory environment of AD. High-level FceRI expression enhances not only binding and uptake of allergens but the activation of LCs upon receptor ligation. LCs in the lesional skin of AD predominantly express CD86 as compared to CD80 $[28,29]$. These data suggest that CD86 expression on LCs plays an important role as co-stimulatory molecules for T cell activation and may account for the increased $\mathrm{Th} 2$ responses that occur after repeated antigen presentation by LCs.

\section{Inflammatory cell infiltration}

In acute $\mathrm{AD}$ skin lesions IL-16, a chemoattractant for CD4+ $\mathrm{T}$ cells, is increased $[30,31]$. The C-C chemokines, RANTES, monocyte chemotactic protein-4, and eotaxin have also been found to be increased in $\mathrm{AD}$ skin lesions and likely contribute to the chemotaxis of eosinophils and Th2 lymphocytes into the skin [32,33]. Several studies suggest a role for cutaneous $\mathrm{T}$ cell-attracting chemokine (CTACK/ CCL27) in the potential attraction of CLA+ T cells to skins [34]. The chemokine receptor CCR3, which is found on eosinophils and Th2 lymphocytes and can mediate the action of eotaxin, RANTES, and MCP-4, has been reported to be increased in non-lesional and lesional skin of patients with $\mathrm{AD}$ [35].

\section{Acute and chronic skin inflammation}

The pathogenesis of $\mathrm{AD}$ is not absolutely clear. Immune response in AD skin may be elicited by multiple triggers, such as aeroallergens and food allergens. APCs that have captured allergens are likely to activate Th2 cells which secrete numerous cytokines, such as IL-4, IL-5, IL-10 and IL-13. Activation of B lymphocytes by IL-4 and IL-13 induce IgE synthesis. IL-5 is mainly responsible for activation and survival of eosinophils.

In the past $\mathrm{AD}$ was considered a disease induced by Th2 lymphocytes. It has now been demonstrated that in $\mathrm{AD}$ skin biphasic response occurs. After an initial Th2 response a switch from Th2 to Th1 response may occur within a few days.

Chronic AD lesions are linked to the prolonged survival of eosinophils and monocyte-macrophages in atopic skin. IL-5 expression during chronic AD likely plays a role in prolonging eosinophil survival and enhancement of their function. In chronic AD an increased GMCSF expression plays an important role in maintaining the survival and function of monocytes, LCs and eosinophils [36]. Epidermal keratinocytes from $\mathrm{AD}$ patients have significantly higher levels of RANTES expression following stimulation with tumor necrosis factor (TNF)- $\alpha$ and IFN- $\gamma$ than keratinocytes from psoriasis patients. This may serve as one mechanism by which the TNF- $\alpha$ and IFN- $\gamma$ production during chronic $\mathrm{AD}$ enhances the chronicity and severity of eczema. Mechanical trauma can also induce the release of TNF- $\alpha$ and many other pro-inflammatory cytokines from epidermal keratinocytes. Thus, chronic scratching plays a role in the perpetuation and elicitation of skin inflammation in $\mathrm{AD}$ [37].

\section{Diagnosis and differential diagnosis}

The American Academy of Dermatology has suggested the following universal diagnostic criteria for atopic dermatitis [38].

A. Essential features which must be present and, if complete, as sufficient for diagnosis:

1. Pruritus

2. Eczematus changes those are acute, sub-acute, or chronic:

a. Typical and age-specific patterns:

i. Facial, neck, and extensor involvement in infants and children

ii. Current or prior flexural lesions in adults/any age.

iii. Sparing of groin and axillary regions

b. Chronic or relapsing course

B. Important features that are seen in most cases, adding support to the diagnosis:

1. Early age at onset

2. Atopy (IgE reactivity)

3. Xerosis

C. Associated features: Clinical associations; help in suggesting the diagnosis of $\mathrm{AD}$ but are too nonspecific to be used for defining or detecting AD for research and epidemiologic studies:

1. Keratosis pilaris/Ichthyosis/Palmar hyperlinearity

2. Atypical vascular responses

3. Perifollicular accentuation/Lichenification/Prurigo

4. Ocular/Periorbital changes

5. Perioral/periauricular lesions

Exclusions: Firm diagnosis of AD depends on excluding conditions such as scabies, allergic contact dermatitis, seborrheic dermatitis, cutaneous lymphoma, ichthyosis, psoriasis, and other primary disease entities.

Table 1 lists a number of inflammatory skin diseases, immunodeficiencies, skin malignancies, genetic disorders, infectious diseases and infestations that share symptoms and signs with $\mathrm{AD}$. These should be considered and ruled out before a diagnosis of AD is made [39].

\section{Immunologic Triggers}

\section{Bacteria, viruses, fungi}

Patients with AD have an increased tendency to develop bacterial, viral and fungal skin infections. S aureus is found in over $90 \%$ of AD skin lesions. One strategy by which $S$. aureus exacerbates or maintains skin inflammation in $\mathrm{AD}$ is by secreting a group of toxins known to act as superantigens, which stimulate marked activation of $\mathrm{T}$ cells and macrophages. Most AD patients make specific IgE antibodies directed against the staphylococcal superantigens found on their skin [40]. 


\begin{tabular}{|l|}
\hline Chronic dermatoses \\
\hline Seborrheic dermatitis \\
\hline Contact dermatitis \\
\hline Nummular eczema \\
\hline Psoriasis \\
\hline Ichthyoses \\
\hline Infections and infestations \\
\hline Scabies \\
\hline Human immunodeficiency virus-associated dermatitis \\
\hline Dermatophytosis \\
\hline Immunodeficiencies \\
\hline Wiskott-Aldrich syndrome \\
\hline Severe combined immunodeficiency syndrome \\
\hline Hyper-IgE syndrome \\
\hline Autoimmune disorders \\
\hline Dermatitis herpetiformis \\
\hline Pemphigus foliaceus \\
\hline Graft-versus-host disease \\
\hline Dermatomyositis \\
\hline Metabolic disorders \\
\hline Zinc deficiency \\
\hline Pyridoxine ( vitamin B6) and niacin \\
\hline Multiple carboxylase deficiency \\
\hline Phenylketonuria \\
\hline Congenital disorders \\
\hline Netherton's syndrome \\
\hline Familial keratosis pilaris \\
\hline Malignancies \\
\hline Cutaneous T cell lymphoma ( mycosis fungoides/Sérazy syndrome) \\
\hline Letterer-Siwe disease \\
\hline
\end{tabular}

Table 1: Differential Diagnosis of Atopic Dermatitis.

The double-stranded DNA viruses, including Herpes Simplex Virus (HSV), molluscum contagiosum virus, and vaccinia virus are also capable of causing more severe and generalized infections in patients with $\mathrm{AD}[41]$.

Eczema herpeticum is a disseminated cutaneous form of HSV and is often considered a medical emergency necessitating prompt systemic antiviral therapy. These data suggest that patients with $\mathrm{AD}$ with greater Th2 might be at greater risk for cutaneous infections that require a robust Th1 response.

There is considerable evidence that subjects with $\mathrm{AD}$ have an unusual propensity for colonization by certain pathogens such as yeast belonging to the genera Malassezia and Candida. A Swedish multicenter study of 132 subjects with $\mathrm{AD}$ revealed that $60 \%$ had a positive skin test response to Malassezia species in comparison with no positive test responses in the non-atopic subjects [42].

Additionally, Candida species have been isolated more commonly from the skin of those with AD compared with those with psoriasis and healthy control subjects [43].

\section{The role of food allergy in the development of AD}

Food allergy has been strongly correlated with the development and persistence of $\mathrm{AD}$, especially during infancy and early childhood. Eigenmann et al. assessed the prevalence of food allergy among children with moderate to severe AD. After an evaluation including oral food challenges, $37 \%$ of these patients were diagnosed with food allergy. Subsequent studies confirmed that a limited number of foods caused clinical symptoms in younger patients with AD. Milk, eggs and peanuts generally cause more than $75 \%$ of the IgE-mediated reactions. If soy, wheat, fish and tree nuts are added to this list of foods, more than $98 \%$ of the foods that cause clinical symptoms would be identified.

The medical history is helpful in establishing diagnosis in cases of immediate-type hypersensitivity reactions with rapid onset of symptoms after apparent ingestion of a certain food. Diagnostic problems may occur in delayed-type hypersensitivity reactions where the adverse reaction to food is not easily identified and when environmental triggers, such as allergens, irritants, infection lead to exacerbations of the disease, thus covering symptoms elicited when consuming the implicated foods. In addition, repeated exposure to the offending food allergens reduces immediate-type hypersensitivity responses, thus making the cause-effect relationship less easy to identify. For breast-fed infants, a maternal dietary history may be helpful because of the passage of food proteins in breast milk [44].

The best general diagnostic approach is to screen children with moderate to severe $\mathrm{AD}$ for sensitivity to eggs, milk, peanuts, soy, wheat, fish and tree nuts (walnut, cashew, pecan) by using skin prick tests or RAST with additional testing for other suspected foods obtained by the history or given by the patients $[44,45]$. Specific IgE antibodies, prick tests and the history sometimes do not correlate with clinical observations. Therefore, food challenges are necessary to show the clinical relevance of the findings. The skin must be scored by an established eczema score before food challenge, $24 \mathrm{~h}$ after and later because otherwise worsening of eczema will be missed [46].

The SCORAD Index (Scoring Atopic Dermatitis Index) is the most commonly used clinical tool to assess the extent and severity of eczema (Table 2) (Figures 1 and 2) [47]. An objective SCORAD score can be used to determine the severity grading for atopic dermatitis into 3 categories: mild (objective SCORAD $<15$ ), moderate (objective SCORAD: $15-40$ ) and severe objective SCORAD $>40$.

\section{Management}

The clinical algorithms for the management of mild-moderate and severe $\mathrm{AD}$ is shown in Figures 3 and 4 respectively [48].

\section{Topical Treatment}

\section{Cutaneous hydration}

Patients with $\mathrm{AD}$ have marked decrease in skin barrier function

Area

An assessment of the affected area (A) as a percentage of the whole body for children under 2 and over 2 years of age is shown in Figures 1 and 2 respectively. The score for each area is added up. The total area is ' $A$ ', which has a possible maximum of $100 \%$.

Intensity

A representative area of eczema is selected. In this area, the intensity of each of the following signs is assessed as none (0), mild (1), moderate (2) or severe (3).

Redness

Swelling

Oozing/crusting

Scratch marks

Skin thickening (lichenification)

Dryness (this is assessed in an area where there is no inflammation) The intensity scores are added together to give ' $\mathrm{B}$ ' (maximum 18).

Subjective symptoms

Subjective symptoms i.e., itch and sleeplessness, are each scored by the patient or relative using a visual analogue scale where 0 is no itch (or no sleeplessness) and 10 is the worst imaginable itch (or sleeplessness). These scores are added to give 'C' (maximum 20).

\section{That Score}

The SCORAD for that individual is $\mathrm{A} / 5+7 \mathrm{~B} / 2+\mathrm{C}$

Table 2: Calculation of Scorad Index. 


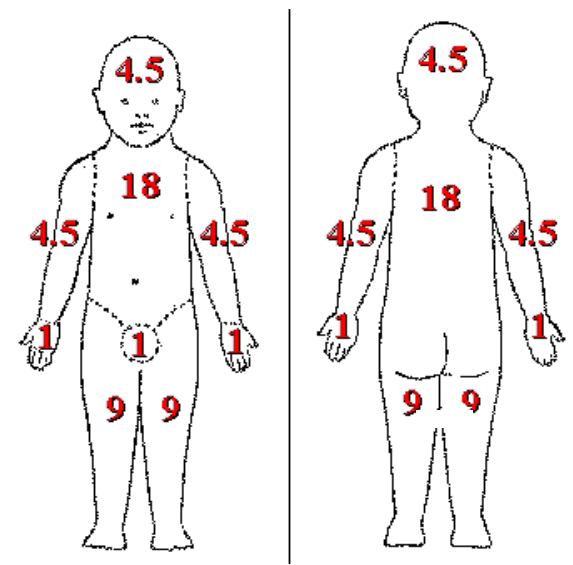

Figure 1: Calculation of the affected body surface area for children unde 2 years of age [47].

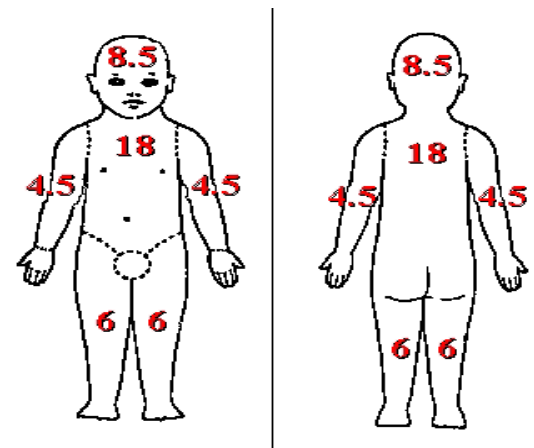

Figure 2: Calculation of the affected body surface area for children over 2 years of age [47].

associated with reduced ceramide levels and enhanced transepidermal water loss. This leads to dry skin (xerosis) contributing to disease morbidity by the development of microfissures and cracks, which serve as portals of entry for skin pathogens, irritants, and allergens. Lukewarm soaking baths for at least 20 minutes, followed by the application of an occlusive emollient to retain moisture can give patients excellent symptomatic relief. Use of an effective emollient combined with hydration therapy will help to restore and preserve the stratum corneum barrier [49,50].

\section{Topical steroids}

Topical corticosteroids and calcineurin inhibitors are used as topical anti-inflammatory agents. Steroids may differ in potency based not only on the active ingredient of the drug but also on the vehicle in which they are formulated. A given concentration of a topical steroid is more potent in an ointment than in a cream. The classification of topical corticosteroids based on potency is shown in Table 3 [51,52].

Glucocorticoids have been the cornerstone of anti-inflammatory treatment for over 50 years. Because of potential side effects, most physicians use topical glucocorticoids for control of acute exacerbation of $\mathrm{AD}$. However, studies suggest that once control of $\mathrm{AD}$ is achieved with daily regimen of topical glucocorticoid, long-term control can be maintained with twice-weekly applications of topical fluticasone to areas that have healed but are prone to developing eczema [53].
Patients should be carefully instructed in the use of topical glucocorticoids to avoid side effects. Topical glucocorticoids should be applied to the skin lesions and emollients should be used over uninvolved skin. Because of their potential side effects the ultrahighpotency glucocorticoids should be used only for very short periods of time and in areas that are lichenified, but not on the face or intertriginous areas. The goal is to use emollients to enhance skin hydration and lower-potency glucocorticoids for maintenance therapy.

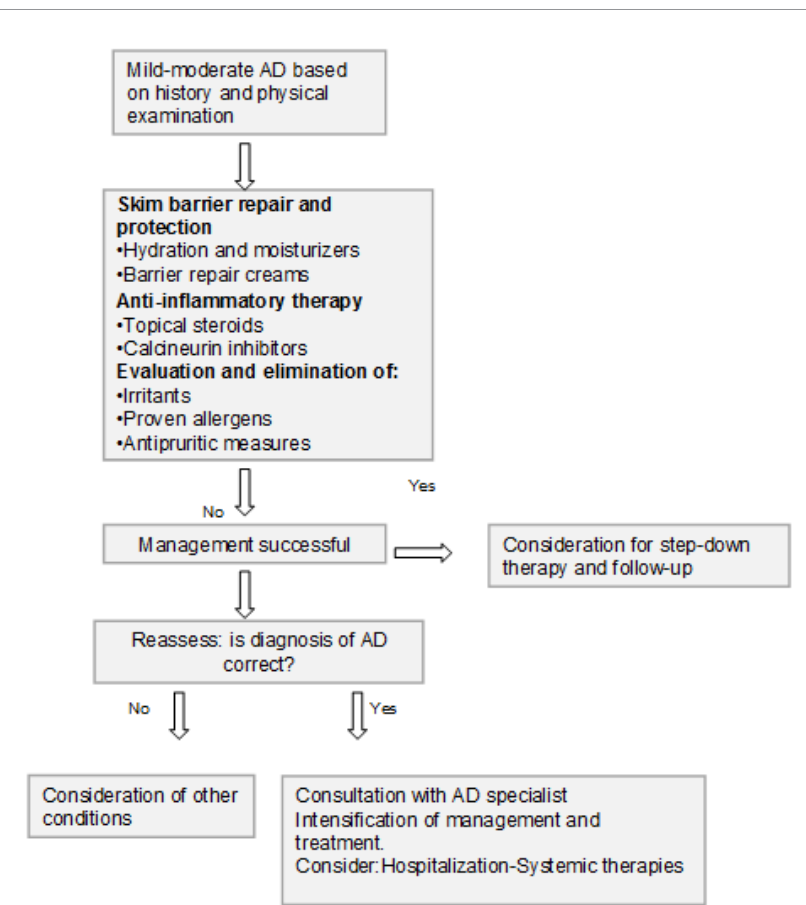

Figure 3: Clinical algorithm for management of mild-moderate atopic dermatitis [37]

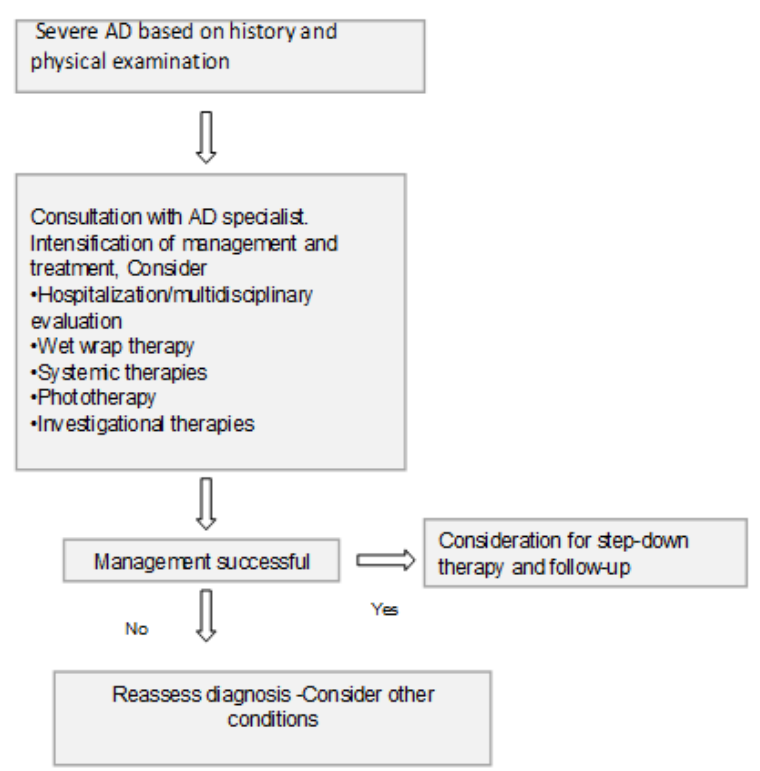

Figure 4: Clinical algorithm for management of severe atopic dermatitis [37]. 


\begin{tabular}{|l|c|}
\hline Class I-mild & \\
\hline Hydrocortisone & $0.5-1.0 \%$ \\
\hline hydrocortisone acetate & $0.5-1.0 \%$ \\
\hline Class II-moderate & $0.05 \%$ \\
\hline aclomethasone dipropionate & $0.02 \%$ \\
\hline betamethasone valerate & $0.05 \%$ \\
\hline betamethasone valerate & $0.02 \%$ \\
\hline triamcinolone acetonide & $0.05 \%$ \\
\hline triamcinolone acetonide & \\
\hline Class III-potent & $0.05 \%$ \\
\hline betamethasone dipropionate & $0.1 \%$ \\
\hline betamethasone valerate & $0.1 \%$ \\
\hline methylprednisolone aceponate & $0.1 \%$ \\
\hline mometasone furoate & \\
\hline
\end{tabular}

Table 3: Classification of topical steroids based on potency [67].

Step 1: clear skin. Use emollients only

Step 2: mild-areas of dry skin, and infrequent itching. Use emollients alone or combined with a topical steroid of mild potency

Step 3: moderate- areas of dry skin, frequent itching and redness. Use emollients with a topical steroid of moderate potency (7-14 days, face 3-5 days use), bandages, (then a topical calcineurin inhibitor such as tacrolimus-but only initiated under specialist dermatological supervision).

Step 4: severe- widespread areas of dry skin, incessant itching, and redness. Use emollients, potent topical steroids (moderate potency on the face or neck), bandages, (then tacrolimus, phototherapy or systemic treatment-but only initiated under specialist dermatological supervision).

Table 4: Treatment of atopic eczema based on a "stepped care plan".

Side effects from topical glucocorticoids can be divided into local and systemic. Local side effects include the development of striae and skin atrophy, while systemic side effects result from suppression of the hypothalamic-pituitary-adrenal axis [48].

\section{Topical calcineurin inhibitors}

Calcineurin inhibitors (tacrolimus and pimecrolimus) have been successfully used in the treatment of AD. Pimecrolimus inhibits Th1 and Th2 cytokine production, reduces antigen-presenting capacity of DCs, mast cells and basophils. Pimecrolimus cream ointment has been approved by the FDA for short-term and intermittent long-term use in mild-moderate $\mathrm{AD}$ for patients 2 years of age and over [54].

Topically applied tacrolimus, a calcineurin inhibitor that acts by binding to FK binding protein, inhibits the activation of a number of key cells involved in $\mathrm{AD}$, including $\mathrm{T}$ cells, LCs, mast cells, and keratinocytes. Tacrolimus ointment has been approved by the Food and Drug Administration (FDA) for short-term and intermittent longterm use in moderate-severe $\mathrm{AD}$ for children 2 to 15 years of age and adults. Unlike topical corticosteroids, tacrolimus ointment does not cause cutaneous atrophy and has been used safely for facial and eyelid eczema. Local burning sensation has been the only common adverse event [55].

Treatment of atopic eczema should be based on a "stepped-care plan" where treatments are stepped up or down depending on the assessment of the state of the child's skin by the physician (Table 4) [56]. Patients who are prescribed steroids or calcineurin inhibitors are advised to use Fingertip Units (FTU) to measure the amount of drug they need to apply in different parts of the body. A fingertip unit is defined as the amount of ointment, cream or other semi-solid dosage form expressed from a tube with a $5 \mathrm{~mm}$ diameter nozzle, applied from the distal skincrease to the tip of the index finger of an adult. The FTU is particularly useful when counseling patients with regards to the amount of topical anti-inflammatory agent they should be applying in order to minimize the side-effects which are associated with their use. The amount of topical anti-inflammatory agent in FTUs that should be applied according to the child's age is shown in Figure 5 [56].

\section{Systemic Therapy}

\section{Systemic glucocorticoids}

The use of systemic glucocorticoids, such as oral prednisone, is rarely indicated in the treatment of chronic AD. The dramatic clinical improvement that may occur with systemic glucocorticoids is frequently associated with a severe rebound flare of $\mathrm{AD}$ following the discontinuation of systemic glucocorticoids. Short courses of oral glucocorticoids may be appropriate for an acute exacerbation of $\mathrm{AD}$ while other treatment measures are being instituted. If a short course of oral glucocorticoids is given, it is important to taper the dosage and begin intensified skin care, particularly with topical glucocorticoids and frequent bathing followed by application of emollients in order to prevent rebound flaring of $\mathrm{AD}$ [48].

\section{Intravenous immunoglobulin}

Intravenous Immunoglobulin has been reported to reduce skin inflammation in patients with refractory $\mathrm{AD}$. The benefits of intravenous immunoglobulin therapy in $\mathrm{AD}$, however, can be rather short-lived, that is, the effects are gone within 3 weeks. Therefore, it is important to intensify local skin care in combination with such alternative therapies [57].

\section{Interferon- $\gamma$}

Interferon- $\gamma$ is known to suppress IgE responses and down-regulate Th2 cell proliferation and function. Reduction in clinical severity of $\mathrm{AD}$ was correlated with the ability of INF- $\gamma$ to decrease total circulating eosinophil counts [48].

\section{Cyclosporine}

Cyclosporine is a potent immunosuppressive drug that acts primarily on T cells by suppressing cytokine transcription. Multiple studies have
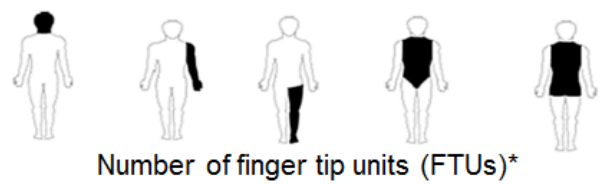

\begin{tabular}{|c|c|c|c|c|c|}
\hline Age & $\begin{array}{l}\text { Face \& } \\
\text { Neck }\end{array}$ & $\begin{array}{l}\text { Arm \& } \\
\text { Hand }\end{array}$ & $\begin{array}{l}\text { Leg \& } \\
\text { Foot }\end{array}$ & $\begin{array}{l}\text { Trunk } \\
\text { (front) }\end{array}$ & $\begin{array}{l}\text { Trunk(back) } \\
\text { inc. buttocks }\end{array}$ \\
\hline Adult & $21 / 2$ & 4 & 8 & 7 & 7 \\
\hline \multicolumn{6}{|l|}{ Children } \\
\hline $\begin{array}{l}3-6 \\
\text { months }\end{array}$ & 1 & 1 & $11 / 2$ & 1 & $11 / 2$ \\
\hline $1-2$ years & $11 / 2$ & $11 / 2$ & 2 & 2 & 3 \\
\hline $3-5$ years & $11 / 2$ & 2 & 3 & 3 & $31 / 2$ \\
\hline $6-10$ years & 2 & $21 / 2$ & $41 / 2$ & $31 / 2$ & 5 \\
\hline
\end{tabular}

${ }^{*}$ One adult fingertip unit(FTU) is the amount of ointment or cream expressed from a tube with a standard $5 \mathrm{~mm}$ diameter nozzle, applied from the distal crease to the tip of the index finger.

Figure 5: The amount of topical anti-inflammatory agent in FTUs that should be applied according to the child's age [56]. 
demonstrated that patients with severe $\mathrm{AD}$, refractory to conventional treatment, can benefit from short-term cyclosporine treatment with reduced skin disease. However, discontinuation of treatment generally results in rapid relapse of skin disease. Elevated serum creatinine or more significant renal impairment and hypertension are specific side effects that are of concern when cyclosporine is used.

Although viral and fungal infections have an increased tendency to develop in $\mathrm{AD}$ skin lesions the most common cause of an exacerbation is colonization of $\mathrm{AD}$ skin lesions with $S$. aureus. A combination of topical or systemic antibiotics and topical corticosteroids result in greater reduction in severity of skin disease compared to topical corticosteroids alone [48].

\section{General aspects on $\mathrm{AD}$ management}

General measures include the avoidance of alkaline soaps which should be replaced by neutral or acidic, as well as avoidance of trigger factors, such as irritants (e.g. detergents), allergens, pathogenic microorganisms and stress.

In cases of moderate or severe eczema the use of antimicrobial cleansers twice a week will unload the increased microbial colonization and contribute substantially to the control of exacerbations [56].

\section{Emollients}

When the diagnosis is definite they should be prescribed in large quantities. In infants they may replace soap or shampoo.

\section{Topical steroids}

A patient should be advised to use mild potency steroids for the face and the neck. However, exception can be made for severe flares which may benefit from short term (3-5 days) use of moderate potency steroids. Steroids of moderate potency or potent corticosteroids are indicated for short periods only (7-14 days) for flares in vulnerable sites such as axillae and groin. If a mild or moderate topical steroid has not controlled the eczema within 7-14 days, the presence of a secondary bacterial or viral infection should be considered. If a potent steroid fails to work over a short time then the child should be referred to a dermatologist [56].

\section{Antihistamines}

Non-sedating antihistamines can be used for a month in children with severe eczema or in children with mild/moderate eczema who suffer from severe itching or urticaria. If the trial is successful it should be continued. A 1-2 week course of a sedating antihistamine can be used for an acute flare of dermatitis, where the child's sleep is being affected [56].

\section{Infections}

Parents should be given information about how to recognize flares and start treatment for flare-ups. Symptoms or signs, such as crying, irritability, blistering the skin, or sudden worsening of the rash may indicate an $\mathrm{AD}$ exacerbation.

A skin culture should be obtained if there is suspicion for skin infection other than $S$. aureus possibly resistant to antibiotics. Localized infections may be treated with the use of topical antibiotics as monotherapy or combined with topical steroids, while an extensive skin infection should be managed with a systemic antibiotic regimen.

In all cases of severe eczema exacerbation an infection with herpes simplex-that is, eczema herpeticum-should be considered.
If so, an immediate referral should be considered for an emergency dermatological opinion and systemic acyclovir should be prescribed immediately. If the rash involves the skin around the eyes, prophylactic ocular acyclovir also needs to be prescribed and an emergency referral for an ophthalmological opinion must also be considered [56].

\section{Referral to dermatological specialist}

An emergency referral to a dermatological specialist should be done when eczema herpeticum is suspected. Emergency referral to a dermatologic within 2 weeks is also required when the eczema is severe and has failed to respond to topical therapy or treatment of bacterial infection has failed.

A routine referral should be done if the diagnosis is uncertain, the standard treatment has not controlled eczema, if contact dermatitis is suspected, if there is recurrent infection of the eczema and if the child's eczema is causing significant social or psychological problems. Figure 4 shows a clinical algorithm for diagnosis and management of $\mathrm{AD}$ [56].

\section{Alternative Therapies}

\section{Phototherapy}

Broad-band ultraviolet $\mathrm{B}$, broad-band ultraviolet $\mathrm{A}$, narrow-band ultraviolet B $(311 \mathrm{~nm})$, UVA-1 $(340-400 \mathrm{~nm})$, and combined UVAB phototherapy can be useful adjuncts in the treatment of AD. Through phototherapy IgE-binding epidermal cells, such as mastocytes, dentritic cells and Langerhan's cells have been significantly reduced.

Short-term adverse effects with phototherapy may include erythema, skin pain, pruritus, and pigmentation; long-term adverse effects include premature skin aging and cutaneous malignancies. Phototherapy should be considered when other therapeutic interventions have failed or considered inappropriate or if the patient's quality of life is significantly impaired $[48,58]$.

\section{Probiotic bacteria and prebiotic fibers}

Many trials have investigated the effect of probiotics and prebiotics on the prevention and treatment of AD. Several Double blind placebo controlled trials have investigated the effect of probiotics and prebiotics either alone or in combinations on AD treatment. Some trials showed a significant reduction of SCORAD score in the intervention groups, while others did not find a significant positive effect on SCORAD score [59]. Another investigating the effect of prebiotics in the development of $\mathrm{AD}$ has shown that the incidence of $\mathrm{AD}$ during the study period was significantly lower in the intervention group than in the placebo, as were the cumulative incidence of recurrent wheezing and allergic urticarial [60].

A review of the year 2011 in regards to the immuno-modulatory effect of probiotics and prebiotics in $\mathrm{AD}$ prevention reported that the use of probiotic and prebiotic supplemented whey hydrolysate formulas is unlikely to reduce atopic diseases, such as $\mathrm{AD}$, in children substantially and that further research is needed in order to determine the future of this interventi on in allergy prevention [61]. A recent review reported that the literature on the use of pro- and prebiotics to prevent $\mathrm{AD}$ is hampered by significant heterogeneity in study methodologies in particular the use of different strains, combinations, doses of organisms and markers of response, making direct comparisons between studies and meaningful meta-analysis very difficult [62]. As a result, the World Allergy Organization has been cautious in a recent position paper, suggesting that further research is needed, before pre- and/or probiotics can be routinely recommended as an effective means to prevent $\mathrm{AD}[63]$. 
Citation: Karagiannidou A, Botskariova S, Farmaki E, Imvrios G, Mavroudi A (2014) Atopic Dermatitis: Insights on Pathogenesis, Evaluation and Management. J Allergy Ther 5: 195. doi:10.4172/2155-6121.1000195

\section{Omalizumab immunotherapy}

A study which investigated the efficacy of omalizumab in moderate-severe $\mathrm{AD}$ in a target population of 20 adults identified that only a subgroup of patients can benefit from omalizumab treatment. All responders were non-fillagrin mutation carriers indicating that the patients with a primary skin barrier deficiency are less likely to benefit from an immunomodulatory therapy with anti-IgE. However, more extended and controlled studies are needed to validate the previous assumption [64].

\section{Allergen specific immunotherapy for AD}

Allergen-specific immunotherapy (allergen-SIT) is the only treatment directed at the cause of IgE-mediated diseases. The effects of SIT for patients with atopic dermatitis have been investigated by a systematic review and meta-analysis of Randomized Controlled Trials (RCTs). A total of 219 patients were included in the SIT groups and 166 patients in the control groups. The results showed that SIT had a significantly positive effect on AD for all 8 RCTs analyzed. Although the previous findings are based on an analysis of a small number of RCTs, with considerable heterogeneity among trials, the review provides physicians with evidence necessary to consider allergen-SIT for patients with $\mathrm{AD}$, especially those with severe uncontrolled disease [65].

\section{Prognosis}

A large prospective longitudinal cohort study of more than 7000 children with mild to moderate $\mathrm{AD}$, which provided 5 years followup, reported lack of resolution. Remission occurred in approximately $15 \%$ of the population. It is probable that AD does not fully resolve in most children with mild to moderate symptoms. Physicians who treat children with mild to moderate AD should tell children and their caregivers that $\mathrm{AD}$ is a lifelong illness $[66,67]$.

\section{References}

1. Leung DY, Bieber T (2003) Atopic dermatitis. Lancet 361: 151-160.

2. Finlay AY (2001) Quality of life in atopic dermatitis. J Am Acad Dermatol 45: S64-66.

3. Johansson SG, Bieber T, Dahl R, Friedmann PS, Lanier BQ, et al. (2004) Revised nomenclature for allergy for global use: Report of the Nomenclature Review Committee of the World Allergy Organization, October 2003. J Allergy Clin Immunol 113: 832-836.

4. Sánchez J, Páez B, Macías a Olmos C, de Falco a (2014) Atopic dermatitis guideline. Position paper from the Latin American Society of Allergy, Asthma and Immunology. Revista Alergia Mexico (Tecamachalco, Puebla, Mexico: 1993), 613: 178-211.

5. Schultz Larsen F, Hanifin JM (2002) Epidemiology of atopic dermatitis. Immunol Allergy Clin North Am 22: 1-24

6. Flohr C, Mann J (2014) New insights into the epidemiology of childhood atopic dermatitis. Allergy 69: 3-16.

7. Forrest S, Dunn K, Elliott K, Fitzpatrick E, Fullerton J, et al. (1999) Identifying genes predisposing to atopic eczema. J Allergy Clin Immunol 104: 1066-1070.

8. Leung DY, Boguniewicz M, Howell MD, Nomura I, Hamid QA (2004) New insights into atopic dermatitis. J Clin Invest 113: 651-657.

9. Mao XQ, Shirakawa T, Yoshikawa T, Yoshikawa K, Kawai M, et al. (1996) Association between genetic variants of mast-cell chymase and eczema. Lancet 348: 581-583.

10. Arkwright PD, Chase JM, Babbage S, Pravica V, David TJ, et al. (2001) Atopic dermatitis is associated with a low-producer transforming growth factor beta(1) cytokine genotype. J Allergy Clin Immunol 108: 281-284.
11. Turner JD, Schwartz RA (2006) Atopic dermatitis. A clinical challenge. Acta Dermatovenerol Alp Pannonica Adriat 15: 59-68.

12. Cookson WO, Ubhi B, Lawrence R, Abecasis GR, Walley AJ, et al. (2001) Genetic linkage of childhood atopic dermatitis to psoriasis susceptibility loci. Nat Genet 27: 372-373.

13. Cookson WO, Moffatt MF (2002) The genetics of atopic dermatitis. Curr Opin Allergy Clin Immunol 2: 383-387.

14. Palmer CN, Irvine AD, Terron-Kwiatkowski A, Zhao Y, Liao $\mathrm{H}$, et al. (2006) Common loss-of-function variants of the epidermal barrier protein filaggrin are a major predisposing factor for atopic dermatitis. Nat Genet 38: 441-446.

15. Wollenberg A, Feichtner K (2013) Atopic dermatitis and skin allergies - update and outlook. Allergy 68: 1509-1519.

16. Ahmad-Nejad P, Mrabet-Dahbi S, Breuer K, Klotz M, Werfel T, et al. (2004) The toll-like receptor $2 \mathrm{R} 753 \mathrm{Q}$ polymorphism defines a subgroup of patients with atopic dermatitis having severe phenotype. J Allergy Clin Immunol 113 565-567.

17. Miller LS, O'Connell RM, Gutierrez MA, Pietras EM, Shahangian A, et al. (2006) MyD88 mediates neutrophil recruitment initiated by IL-1R but not TLR2 activation in immunity against Staphylococcus aureus. Immunity 24: 79-91.

18. Rothenbacher D, Weyermann M, Beermann C, Brenner H (2005) Breastfeeding soluble CD14 concentration in breast milk and risk of atopic dermatitis and asthma in early childhood: birth cohort study. Clin Exp Allergy 35: 1014-1021.

19. Rieg S, Steffen H, Seeber S, Humeny A, Kalbacher H (2005) Deficiency of dermcidin-derived antimicrobial peptides in sweat of patients with atopic dermatitis correlates with an impaired innate defense of human skin in vivo. J Immunol 174: 8003-8010.

20. Mrowietz U, Konter U, Traut R, Schröder JM, Christophers E (1988) Atopic dermatitis: influence of bacterial infections on human monocyte and neutrophil granulocyte functional activities. J Allergy Clin Immunol 82: 1027-1036.

21. Higashi N, Gesser B, Kawana S, Thestrup-Pedersen K (2001) Expression of IL18 mRNA and secretion of IL-18 are reduced in monocytes from patients with atopic dermatitis. J Allergy Clin Immunol 108: 607-614.

22. Hanifin JM, Chan SC, Cheng JB, Tofte SJ, Henderson WR Jr, et al. (1996) Type 4 phosphodiesterase inhibitors have clinical and in vitro anti-inflammatory effects in atopic dermatitis. J Invest Dermatol 107: 51-56.

23. Jirapongsananuruk O, Hofer MF, Trumble AE, Norris DA, Leung DY (1998) Enhanced expression of B7.2 (CD86) in patients with atopic dermatitis: a potential role in the modulation of IgE synthesis. J Immunol 160: 4622-4627.

24. Boguniewicz M, Leung DY (2006) 10. Atopic dermatitis. J Allergy Clin Immunol 117: S475-480.

25. Hamid Q, Naseer T, Minshall EM, Song YL, Boguniewicz M, et al. (1996) In vivo expression of IL-12 and IL-13 in atopic dermatitis. J Allergy Clin Immunol 98: 225-231.

26. Trautmann A, Akdis M, Schmid-Grendelmeier $P$, Disch $R$, Bröcker EB, et al. (2001) Targeting keratinocyte apoptosis in the treatment of atopic dermatitis and allergic contact dermatitis. J Allergy Clin Immunol 108: 839-846.

27. von Bubnoff D, Geiger E, Bieber T (2001) Antigen-presenting cells in allergy. J Allergy Clin Immunol 108: 329-339.

28. Ohki O, Yokozeki H, Katayama I, Umeda T, Azuma M, et al. (1997) Functional CD86 (B7-2/B70) is predominantly expressed on Langerhans cells in atopic dermatitis. Br J Dermatol 136: 838-845.

29. Schuller E, Teichmann B, Haberstok J, Moderer M, Bieber T, et al. (2001) In situ expression of the costimulatory molecules CD80 and CD86 on langerhans cells and inflammatory dendritic epidermal cells (IDEC) in atopic dermatitis. Arch Dermatol Res 293: 448-454.

30. Laberge S, Ghaffar O, Boguniewicz M, Center DM, Leung DY, et al. (1998) Association of increased CD4+ T-cell infiltration with increased IL-16 gene expression in atopic dermatitis. J Allergy Clin Immunol 102: 645-650.

31. Reich K, Hugo S, Middel P, Blaschke V, Heine A, et al. (2002) Evidence for a role of Langerhans cell-derived IL-16 in atopic dermatitis. J Allergy Clin Immunol 109: 681-687.

32. Taha RA, Minshall EM, Leung DY, Boguniewicz M, Luster A, et al. (2000) Evidence for increased expression of eotaxin and monocyte chemotactic protein-4 in atopic dermatitis. J Allergy Clin Immunol 105: 1002-1007. 
Citation: Karagiannidou A, Botskariova S, Farmaki E, Imvrios G, Mavroudi A (2014) Atopic Dermatitis: Insights on Pathogenesis, Evaluation and Management. J Allergy Ther 5: 195. doi:10.4172/2155-6121.1000195

33. Morita E, Kameyoshi Y, Hiragun T, Mihara S, Yamamoto S (2001) The C-C chemokines, RANTES and eotaxin, in atopic dermatitis. Allergy 56: 194-195.

34. Morales J, Homey B, Vicari AP, Hudak S, Oldham E, et al. (1999) CTACK, a skin-associated chemokine that preferentially attracts skin-homing memory $T$ cells. Proc Natl Acad Sci U S A 96: 14470-14475.

35. Yawalkar N, Uguccioni M, Schärer J, Braunwalder J, Karlen S, et al. (1999) Enhanced expression of eotaxin and CCR3 in atopic dermatitis. J Invest Dermatol 113: 43-48.

36. Bratton DL, Hamid Q, Boguniewicz M, Doherty DE, Kailey JM, et al. (1995) Granulocyte macrophage colony-stimulating factor contributes to enhanced monocyte survival in chronic atopic dermatitis. J Clin Invest 95: 211-218.

37. Giustizieri ML, Mascia F, Frezzolini A, De Pità O, Chinni LM, et al. (2001) Keratinocytes from patients with atopic dermatitis and psoriasis show a distinct chemokine production profile in response to T cell-derived cytokines. J Allergy Clin Immunol 107: 871-877.

38. Eichenfield LF, Tom WL, Chamlin SL, Feldman SR, Hanifin JM, et al. (2014) Guidelines of care for the management of atopic dermatitis: section 1. Diagnosis and assessment of atopic dermatitis. J Am Acad Dermatol 70: 338-351.

39. Leung D (2003) Atopic Dermatitis in Pediatric Allergy: Principles and Practice. Mosby. St. Louis pp: 561-573

40. Breuer K, Wittmann M, Bösche B, Kapp A, Werfel T (2000) Severe atopic dermatitis is associated with sensitization to staphylococcal enterotoxin B (SEB). Allergy 55: 551-555.

41. Wollenberg A, Wetzel S, Burgdorf WH, Haas J (2003) Viral infections in atopic dermatitis: pathogenic aspects and clinical management. J Allergy Clin Immunol 112: 667-674.

42. Johansson C, Sandström MH, Bartosik J, Särnhult T, Christiansen J, et al. (2003) Atopy patch test reactions to Malassezia allergens differentiate subgroups of atopic dermatitis patients. Br J Dermatol 148: 479-488.

43. Arzumanyan VG, Magarshak OO, Semenov BF (2000) Yeast fungi in patients with allergic diseases: species variety and sensitivity to antifungal drugs. Bull Exp Biol Med 129: 601-604.

44. Jones SM, Wesley Burks (2003) Atopic Dermatitis and Food Hypersensitivity in Pediatric Allergy: Principles and Practice Mosby, St. Louis, Inc pp 538-545

45. Krakowski AC, Eichenfield LF, Dohil MA (2008) Management of atopic dermatitis in the pediatric population. Pediatrics 122: 812-824.

46. Werfel T, Ballmer-Weber B, Eigenmann PA, Niggemann B, Rancé F, et al. (2007) Eczematous reactions to food in atopic eczema: position paper of the EAACI and GA2LEN. Allergy 62: 723-728.

47. The European Task Force on Atopic Dermatitis (1993). Severity scoring of atopic dermatitis: the SCORAD index. Consensus Report of the European Task Force on Atopic Dermatitis. Dermatology 186: 23-31.

48. Boguniewicz M, Leung D (2010) Management of atopic dermatitis in Pediatric Allergy: Principles and Practice 2nd edition. Elsevier Saunders, Philadelphia pp: $564-574$

49. Elias PM (2008) Barrier repair trumps immunology in the pathogenesis and therapy of atopic dermatitis. Drug Discov Today Dis Mech 5: e33-33e38.

50. Vickery BP (2007) Skin barrier function in atopic dermatitis. Curr Opin Pediatr 19: 89-93.

51. Simon C (2008) Childhood atopic eczema. InnovAiT 1: 423-429.

52. Wolter S, Price HN (2014) Atopic dermatitis. Pediatr Clin North Am 61: 241 260.

53. Van Der Meer JB, Glazenburg EJ, Mulder PG, Eggink HF, Coenraads PJ (1999) The management of moderate to severe atopic dermatitis in adults with topical fluticasone propionate. The Netherlands Adult Atopic DermatitisStudy Group. Br J Dermatol 140: 1114-1121

54. Zuberbier T, Chong SU, Grunow K, Guhl S, Welker P (2001) The ascomycin macrolactam pimecrolimus (Elidel, SDZ ASM 981) is a potent inhibitor of mediator release from human dermal mast cells and peripheral blood basophils, Allergy Clin Immunol 108: 275-280.

55. Reitamo S (2001) Tacrolimus: a new topical immunomodulatory therapy for atopic dermatitis. J Allergy Clin Immunol 107: 445-448.

56. National Institute for Clinical Excellence (2007) Atopic eczema in children: management of atopic eczema in children from birth up to age of 12 years. NICE Clinical Guidelines.

57. Jolles S (2002) A review of high-dose intravenous immunoglobulin treatment for atopic dermatitis. Clin Exp Dermatol 27: 3-7.

58. Darné S, Leech SN, Taylor AE (2014) Narrowband ultraviolet B phototherapy in children with moderate-to-severe eczema: a comparative cohort study. $\mathrm{Br} \mathrm{J}$ Dermatol 170: 150-156.

59. van der Aa LB, Heymans HS, van Aalderen WM, Sprikkelman AB (2010) Probiotics and prebiotics in atopic dermatitis: review of the theoretical background and clinical evidence. Pediatr Allergy Immunol 21: e355-367.

60. Arslanoglu S, Moro GE, Schmitt J, Tandoi L, Rizzardi S, et al. (2008) Early dietary intervention with a mixture of prebiotic oligosaccharides reduces the incidence of allergic manifestations and infections during the first two years of life. J Nutr 138: 1091-1095.

61. Mavroudi A, Xinias I (2011) Dietary interventions for primary allergy prevention in infants. Hippokratia 15: 216-222.

62. Flohr C, Mann J (2014) New approaches to the prevention of childhood atopic dermatitis. Allergy 69: 56-61.

63. Fiocchi A, Burks W, Bahna SL, Bielory L, Boyle RJ, et al. (2012) Clinical Use of Probiotics in Pediatric Allergy (CUPPA): A World Allergy Organization Position Paper. World Allergy Organ J 5: 148-167.

64. Hotze M, Baurecht $\mathrm{H}$, Rodríguez E, Chapman-Rothe N, Ollert M, et al. (2014) Increased efficacy of omalizumab in atopic dermatitis patients with wild-type filaggrin status and higher serum levels of phosphatidylcholines. Allergy 69 132-135.

65. Bae JM, Choi YY, Park CO, Chung KY, Lee KH (2013) Efficacy of allergenspecific immunotherapy for atopic dermatitis: a systematic review and metaanalysis of randomized controlled trials. J Allergy Clin Immunol 132: 110-117.

66. Margolis JS, Abuabara K, Bilker W, Hoffstad O, Margolis DJ (2014) Persistence of Mild to Moderate Atopic Dermatitis. JAMA Dermatology 1-8.

67. Michael Lee (1998) The role of corticosteroids in dermatology. Aust Prescr 21 9-11. 